\title{
IS THE LAST YEARS ABRUPT WARMING IN THE NATIONAL OBSERVATORY OF ATHENS RECORDS A CLIMATE CHANGE MANIFESTATION?
}

\author{
C.C. REPAPIS ${ }^{1, *}$ \\ C.M. PHILANDRAS ${ }^{1}$ \\ P.D. KALABOKAS ${ }^{1}$ \\ P. ZANIS ${ }^{1}$ \\ C.S. ZEREFOS ${ }^{2}$
}

Received: 01/09/06

Accepted: 30/10/06

\author{
${ }^{1}$ Research Center for Atmospheric Physics and Climatology \\ 3rd September Str. 131, GR112 51 Athens, Greece \\ ${ }^{2}$ National Observatory of Athens \\ P.O. Box 200048, Thissio, GR118 10, Athens, Greece
}

*to whom all correspondence should be addressed:

Tel./Fax: +30 2108832048

e-mail: phatmcli@otenet.gr

\begin{abstract}
Instrumental data time series show an average global warming of approximately $0.9^{\circ} \mathrm{C}$ over the last century. Eastern Mediterranean air temperature follows the northern hemisphere $(\mathrm{NH})$ secular trend till 1970s, while the $\mathrm{NH}$ warming of the last 30 years is not noticeable in the eastern Mediterranean till 1990s. National Observatory of Athens (NOA) meteorological time series start from the last decades of the $19^{\text {th }}$ Century, therefore are at first suitable for detection of long term trends in the region. In this study we investigate whether the abrupt increase of the NOA air temperature time series, which appears during the last few years, is the finger-print of the broader scale climatic change or it is a discontinuity in the record of urban effect or of station's problems origin. It is shown that NOA air temperature records display a statistically significant discontinuity attributable to change of the station thermometers on 1995 and therefore NOA records must be treated with caution for long term air temperature trends detection.
\end{abstract}

KEYWORDS: Air Temperature Trends, Homogeneity, Athens - Greece.

\section{INTRODUCTION}

In recent decades there is a growing interest in climate variability and climate change related to the study of the global warming considered as a consequence of the anthropogenic enhancement of the greenhouse effect (IPCC, 2001). There is a growing scientific consensus that current levels of hemispheric and global mean air temperature are unusually high in the context of the instrumental record and multiproxy paleotemperature reconstructions over the last millennium (Luterbacher et al., 2004). The almost $0.9{ }^{\circ} \mathrm{C}$ at global scale warming over the last century has not occurred monotonically but with two principal warming phases in the earlier and the later decades of the 20th century (1915-1940 and since 1975) and a slight cooling phase in between. The patterns of warming and cooling rates indicate extensive spatial, seasonal and temporal variability, also regional temperature trends typically exhibit quite different behavior from that behavior evident for the hemispheric or global mean (Jones and Mann, 2004).

It has been shown that eastern Mediterranean air temperature time series follow the northern hemisphere secular trend from late $19^{\text {th }}$ Century to 1970s (Repapis and Philandras, 1988). Nevertheless the warming trend of the last 25-30 years that is well documented for the $\mathrm{NH}$ and the global average appears only since mid 1990s in the eastern Mediterranean region and Greece in particular (Repapis and Philandras 1997, Saaroni et al., 2003, Feidas et al., 2004). National Observatory of Athens (NOA) air temperature time series display an abrupt increase during the last few years, especially in the summer records. Change from mercury to automatic 
electronic Pt 100 thermometers on May 1995 is reported in the station's metadata. The NOA time series are used in many studies for assessing climatic changes as being the longest records in the region. Hence, we believe that is very important to investigate whether that jump in the record is due to the broader scale climate change variation, natural and/or anthropogenic, or to inhomogeneity in the record due either to urban effect or to observational procedures inherent factors, although to separate the one factor from the other is a difficult task as undoubtedly all of them contribute to the final result.

\section{DATA AND ANALYSIS.}

The data used in this study are the following:

a. Monthly mean, surface air temperature for the meteorological station of the National Observatory of Athens, NOA ( $37^{0} 58 \mathrm{~N} 23^{0} 43 \mathrm{E}, 107 \mathrm{~m}$ a.s.I.), for the period 1891-2004.

b. Monthly mean surface air temperature for the Hellenic Meteorological Service stations of (i) Hellinicon airport (southern border of the city, near the coast, $37^{0} 54^{\prime} \mathrm{N}, 23^{0} 44^{\prime} \mathrm{E}, 15 \mathrm{~m}$ a.s.l), (ii) Nea Philadelfia (inside the city, north of NOA, $38^{0} 03^{\prime} \mathrm{N}, 23^{0} 40^{\prime} \mathrm{E}, 136 \mathrm{~m}$ a.s.l.) and (iii) Tatoi airport (northern border of the city, $38^{0} 07^{\prime} \mathrm{N}, 23^{0} 47^{\prime} \mathrm{E}, 237 \mathrm{~m}$ a.s.l) for the period 1956-2001.

c. Average monthly mean surface air temperature (anomalies from the 1961-1990 reference period) of the $5^{0}$ lat. $X 5^{0}$ long. data sets CRUTEM2 of the Climatic Research Unit (Jones and Moberg, 2003), (i) for the Northern Hemisphere average (ii) for the grid-box, centered on the $37^{0} 30^{\prime} \mathrm{N}, 22^{0} 30^{\prime} \mathrm{E}$ grid, covering almost the entire continental Greece (thereafter $\mathrm{CRU}$ ), and (iii) for the grid boxes which cover the eastern Mediterranean region, $30^{\circ}-40^{\circ} \mathrm{N}$ to $20^{\circ}-35^{\circ} \mathrm{E}$, for the period $1891-2004$.

d. Average monthly mean surface air temperature time series of the $10^{\prime}$ lat. $\times 10^{\prime}$ long. gridbox which refers to the square area of $10^{\prime}$ to the north and $10^{\prime}$ to the east of the $37^{\circ} 50^{\prime} \mathrm{N}$, $23^{\circ} 40^{\prime} \mathrm{E}$ grid that covers almost the entire Athens basin (thereafter CRUTS1.2), from the Climatic Research Unit data sets CRUTS1.2 (Jones et al. 1999, Mitchell et al., 2003), for the period 1901-2000.

In order to test the homogeneity of the National Observatory of Athens last decades time series, the standard normal homogeneity test (SNHT) for single shift of the mean level as modified by Alexandersson and Moberg (1997), is used. As these authors state the test is intended primarily for studies of artificial warming at temperature monitoring stations located in urban environments. This test detects gradual changes of the mean value in a candidate time series compared with a homogeneous reference series.

A sequence of standardized differences $z_{i}$ between the candidate and the reference time series of neighboring stations is constructed,

$Z_{i}=\left(Q_{i}-\bar{Q}\right) / \sigma_{Q}$ and $Q_{i}=\left(Y_{i}-\bar{Y}\right)-\left(X_{i}-\bar{X}\right)$

where $\sigma_{Q}$ is the standard deviation of $Q, Y_{i}$ denotes a specific value of the candidate time series at time unit $i$ and $X_{i}$ the corresponding value of the reference series. The standard normal homogeneity tests are applied to $Z_{i}$ series.

Alexandersson (1986) obtained the test statistic as,

$\operatorname{Tmax}=\max \{T a\}=\max \left\{a \bar{z}_{1}^{2}+(n-a) \bar{z}_{2}^{2}\right\}$

where $\bar{Z}_{1}$ and $\bar{Z}_{2}$ are the arithmetic averages of the $z_{i}$ sequence before and after the shift. The value of $a$ corresponding to this maximum is the year most probable for the break. If Tmax is above a certain critical level we reject the null hypothesis of homogeneity at the corresponding significance level.

The National Observatory of Athens air temperature record of the last decades is also tested for discontinuity with the Easterling and Peterson (1995) developed variation of the Solow (1987) technique, which use regression approach on difference series created by subtracting a homogenous reference series from the candidate station series. First a simple linear 
regression is fitted to the entire difference series and the residual sum of squares $\left(R S S_{1}\right)$ is calculated. Next for each point in the difference series a simple linear regression is fitted to the difference series before that point and another simple linear regression is fitted to the part of the difference series after that point. The $R S S_{2}$ is the sum of the RSSs calculated from each of the two regressions before and after that point. Hence for each point of the difference series a two-phase regression is fitted and the $R S S_{2}$ is calculated. The point with the minimum $R S S_{2}$ is flagged as the location of potential discontinuity. To test the significance of the two-phase fit we use the following likelihood ratio statistic from Solow (1987).

$$
U=\frac{\left[\left(R S S_{1}-R S S_{2}\right) / 3\right]}{\left[R S S_{2} /(n-4)\right]}
$$

This test statistic is $F$ distributed with 3 and $(n-4)$ degrees of freedom.

We also test the difference in the means of the two sub-periods of the difference series before and after the discontinuity point using Student's t-test.

\section{DISCUSSION AND RESULTS}

The air temperature inside the city of Athens evidently presents non negligible modifications from site to site because of land use differences and topography, but also differs relatively to the corresponding of its rural environment air temperature and manifests the known effect of the "urban heat island" mainly in the minimum air temperature (Katsoulis and Theoharatos, 1985; Repapis and Metaxas, 1986; Englezou et al., 1993; Chronopoulou-Sereli, 1993).

National Observatory of Athens is located on top of a hill (107 $\mathrm{m}$ a.s.l., $5 \mathrm{Km}$ inland from the coast) which was outside of the urban net of Athens till the third decade of the $20^{\text {th }}$ Century. The immediate environment of the Observatory on the hill, where sparse pine trees grow, remains unaltered since the beginning of the $20^{\text {th }}$ Century in spite of the fact that the city expanded strikingly, especially after the World War II and surrounded the hill. The population of Athens increased from about a quarter of a million at the beginning of the $20^{\text {th }}$ Century to almost 4 millions inhabitants nowadays.

Many papers have dealt with the issue whether NOA meteorological records have been affected from urbanization and if so, since when and to what degree (Katsoulis and Theoharatos, 1985; Repapis and Metaxas, 1985; Philandras et al., 1999).

Although since late 1920s there must have been to some extent urbanization effect on the air temperature in the center of the city, which was at that time the most heavily loaded area by inhabitants, vehicles, industries and other urban activities, the assessment of that effect is a quite difficult task because besides NOA observations only sparse data are available in the Athens basin before 1950s. Nevertheless the air temperature trends were uniform over Athens as well as its rural surroundings till the 1970 s and no important urban influence is noticed at NOA before 1970s, probably because of its physical configuration described above. Since late 1970 s the difference of the air temperature maximum values of the warm season between NOA and the rural environment increases about $1^{\circ} \mathrm{C}$ most likely because of the urban effect (Repapis and Metaxas, 1985; Philandras et al., 1999; Philandras and Nastos, 2002).

In Figure 1 the well-known annual mean surface air temperature time series of the Northern Hemisphere is displayed (9-year Gaussian smoothing) along with the corresponding time series for the entire eastern Mediterranean region $\left(30^{\circ}-40^{\circ} \mathrm{N}, 20^{\circ}-35^{\circ} \mathrm{E}\right)$ and for the continental Greece $\left(35^{\circ}-40^{\circ} \mathrm{N}, 20^{\circ}-25^{\circ} \mathrm{E}\right)$. It is obvious that eastern Mediterranean region only recently exhibits the warming phase which $\mathrm{NH}$ as a whole has started two decades earlier. (Repapis and Philandras, 1988 ; 1997 ; Metaxas et al., 1991).

In this study we focus our investigation mainly to the recent air temperature trend. The upper curve of Figure 2 presents the average annual mean air temperature anomalies for the entire continental Greece $\left(35^{\circ}-40^{\circ} \mathrm{N}, 20^{\circ}-25^{\circ} \mathrm{E}\right.$, CRUTEM2 data). The lower curves of this figure present the annual mean air temperature values for NOA (asterisks) and the average annual mean air temperature for Athens basin region (dots, CRUTS1.2 data). Heavy lines represent 9-year Gaussian smoothing. The long term as well as the short-term fluctuations of the three curves are almost identical except for the last decade the case of which we will discuss in a 
later paragraph. The high correlation coefficients between the values of these three data sets, shown in Table 1 confirm the similarity of the short and long-term variability between NOA values and the average values of the Athens basin and of these two data sets with the average values of the entire Greek region.

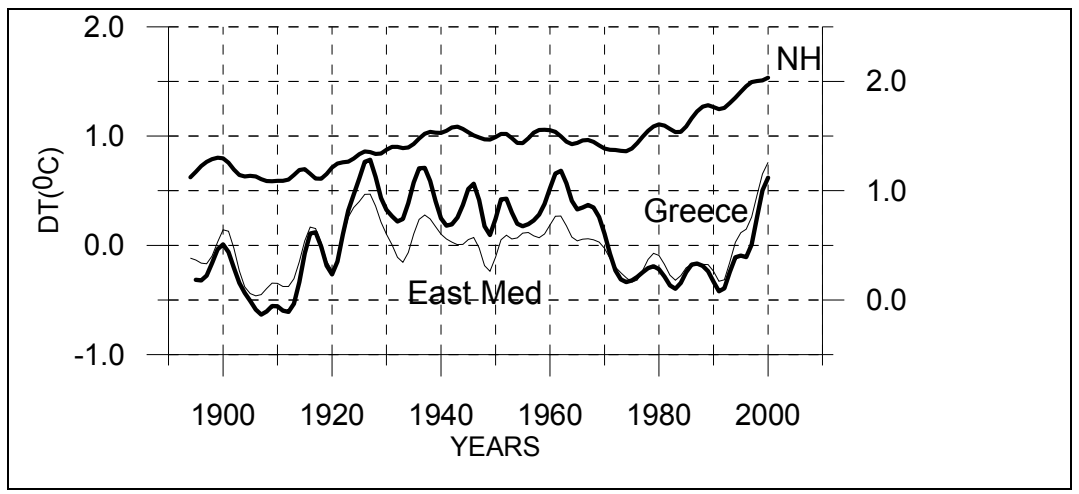

Figure 1. Gaussian 9-year smoothing of the annual mean air temperature anomalies from the reference period 1961-90, averaged over Northern Hemisphere (upper heavy line, right scale), averaged over eastern Mediterranean region, (light line, left scale) and averaged over the entire continental Greece (lower heavy line, left scale). Data sets from Climatic Research Unit (CRUTEM2, Jones and Moberg 2003).

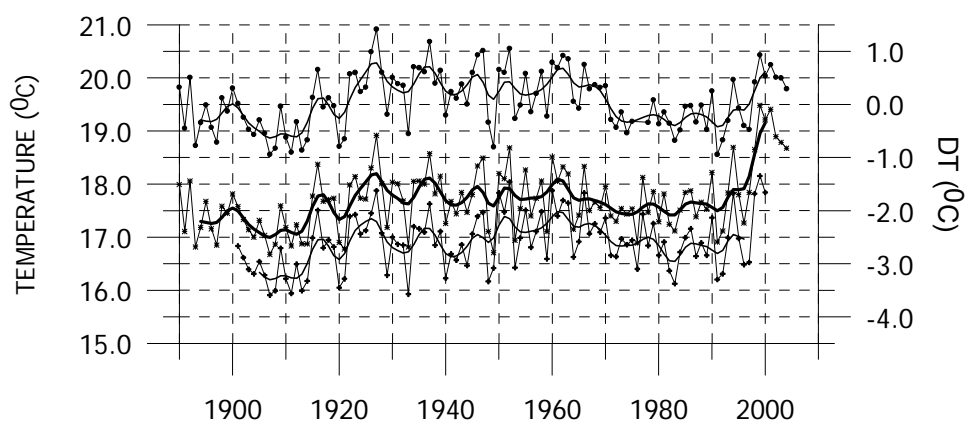

Figure 2. Average annual mean air temperature anomalies (right scale) for the grid box (CRUTEM2, Jones and Moberg 2003) which covers the entire continental Greece (dots, upper curve). Annual mean air temperature (left scale) for NOA (asterisks, middle curve) and the average annual mean air temperature for the grid box (CRUTS1.2, Mitchell et al 2003) which almost covers Athens basin (crosses, lower curve). Heavy lines are 9-year Gaussian smoothing.

These high correlations permit us to investigate the fluctuations of NOA air temperature time series comparing them with the grid boxes averaged time series and in particular with CRUTEM2 as these data are updated to 2004 while CRUTS1.2 ended on 2000.

The annual, summer and winter mean air temperature time series of the National Observatory of Athens (asterisks) and the CRU grid data (dots), both data sets as departures from the 1961-1990 reference period averages, are shown in Figure 3. The upper curve in each panel is the time series of the differences of NOA minus CRU values.

On top of each time series the corresponding 9-year or 9-season Gaussian smoothing is plotted. The correlation coefficients between NOA and CRU time series, for the entire period, are high (annual $r=0.87$; winter $r=0.95$; summer $r=0.93$ ). The short and long term fluctuations of the NOA and CRU grid time series shown in Figure 3 are almost identical up to 1970 when NOA summer and annual air temperature exhibits a warming of $0.3-0.4^{0} \mathrm{C}$ till mid $1990 \mathrm{~s}$. That warming must be attributed to the urban effect of Athens city as has been demonstrated by many scientists mentioned above. In mid 1990s, a remarkable discontinuity is evident in the difference between NOA annual mean air temperature time series and the corresponding 
average over the entire continental Greece CRU corresponding series. This discontinuity appears in both winter and summer seasonal time series and particularly more intense in the summer values (Figure 3, middle and lower panels).

From the above discussion it is obvious that the jump of the NOA annual mean air temperature on mid 1990s cannot be attributed to climate change as does not appear in the averaged CRU time series for the entire Greek region. From Figure 3 undoubtedly we can deduce that mainly summer contributes to the large difference of the last eight years owing, in general, to both mean maximum and mean minimum summer air temperature as we can conclude from Figure 4 in which these NOA time series are shown.

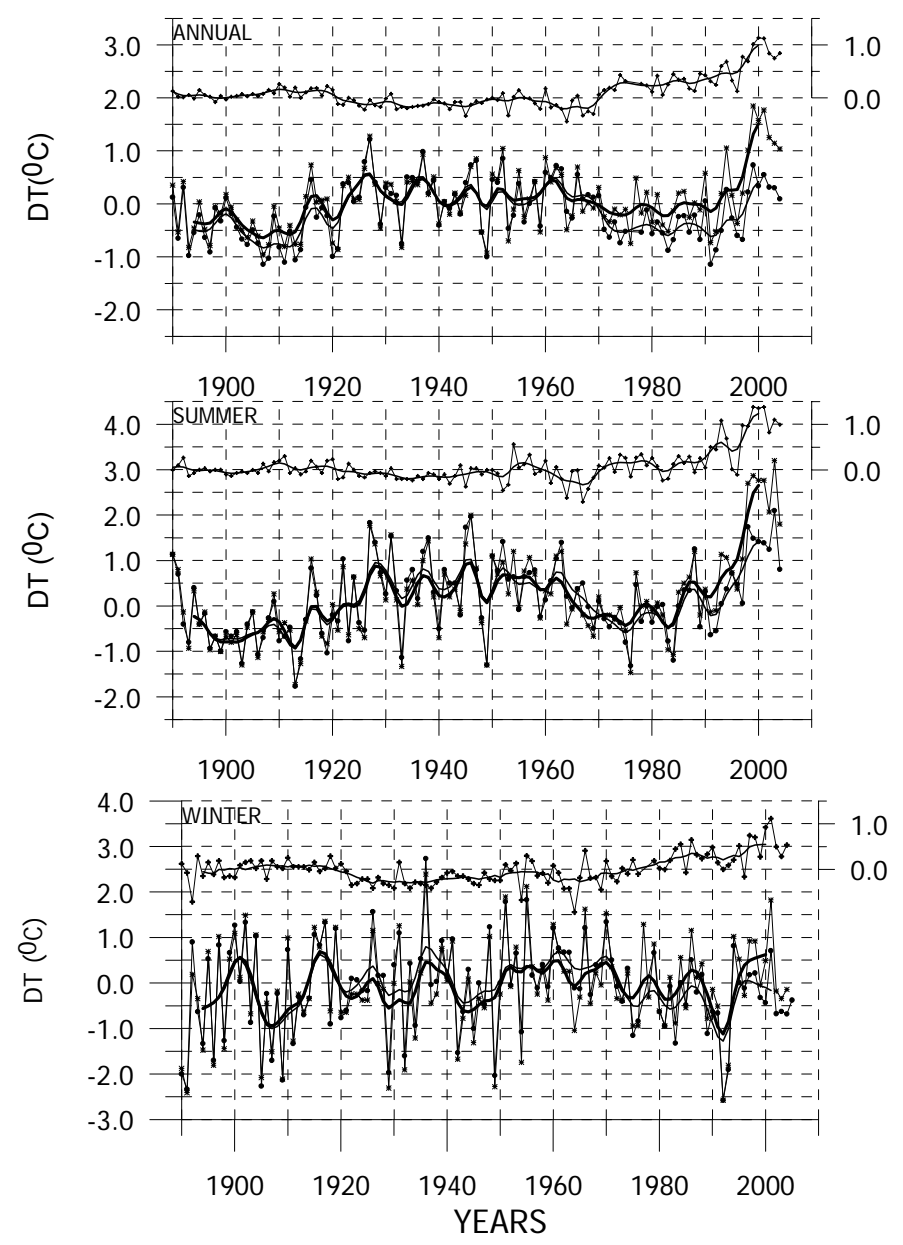

Figure 3. Annual (upper panel), summer (middle) and winter (lower) mean air temperature time series of the National Observatory of Athens (asterisks) and the CRU grid data (dots), as departures from the 1961-1990 period averages, are shown. The upper curve in each panel is the time series of the differences of NOA minus CRU values. On top of each time series the corresponding 9-year or 9-season Gaussian smoothing is plotted. (CRUTM2 data sets Jones and Moberg 2003).

Rejecting the possibility that climatic change is responsible for the latest jump on the NOA air temperature records we attempted to investigate if this jump is due to urban effect.

In Athens basin, besides NOA station, there are three other stations in operation, namely Hellinicon airport, Nea Philadelfia and Tatoi airport which are situated along the major axis of Athens basin from the coast in the South to the inland in the North. The correlation coefficients of deseasonalized monthly air temperature values of NOA versus the other three stations are very high (Table 2 ). 


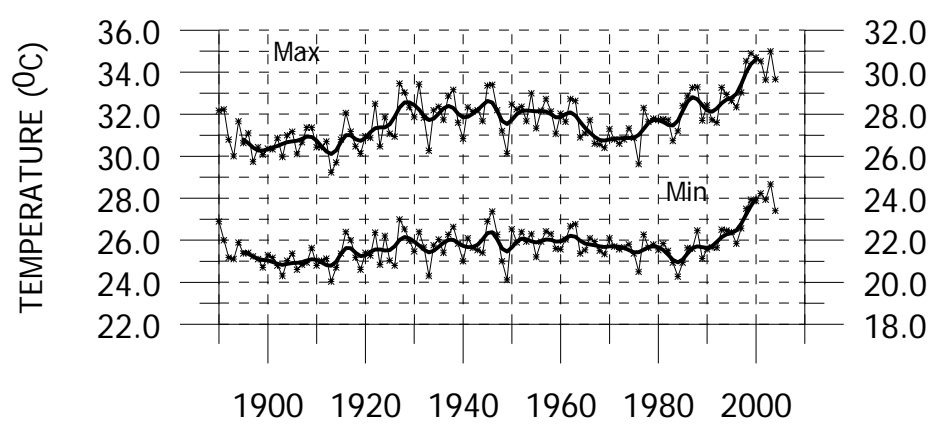

Figure 4. Summer mean maximum (upper curve, left scale) and mean minimum (lower curve, right scale) air temperature time series for NOA (heavy lines, 9-year Gaussian smoothing).

Table 1. Correlation coefficients among the annual values, of the three data sets, 1901-2000.

\begin{tabular}{lcc}
\hline & $\begin{array}{c}\text { CRU }\left(5^{\circ} \times 5^{\circ}\right) \\
35^{0}-40^{0} \mathrm{~N}, 20^{0}-25^{\circ} \mathrm{E}\end{array}$ & $\begin{array}{c}\text { CRUTS } 1.2\left(10^{\prime} \times 10^{\prime}\right) 37^{\circ} 50^{\prime}- \\
38^{\circ} 00^{\prime} \mathrm{N},\end{array}$ \\
\hline NOA & .87 & $23^{0} 40^{\prime}-23^{0} 50^{\prime} \mathrm{E}$ \\
\hline CRUTS 1.2 & .88 & .94 \\
\hline
\end{tabular}

Table 2. Correlation coefficients among the monthly-deseasonalized values of the different stations and the $\mathrm{CRU}$ data (grid $37^{0} 30^{\prime} \mathrm{N}, 22^{0} 30^{\prime} \mathrm{E}$ ) for $1956-2001$.

\begin{tabular}{clcccc}
\hline & CRU & $\mathrm{H}$ & $\mathrm{P}$ & $\mathrm{T}$ & $\mathrm{HPT}$ \\
\hline $\begin{array}{c}\text { NOA, NATIONAL } \\
\text { OBSERVATORY } \\
\text { OF ATHENS }\end{array}$ & 0.92 & 0.96 & 0.97 & 0.94 & 0.97 \\
\hline $\mathrm{H}$, HELLINICON AIRPORT & 0.94 & & 0.94 & 0.94 & 0.98 \\
\hline P, NEA PHILADELFIA & 0.90 & & & 0.96 & 0.98 \\
\hline T, TATOI & 0.92 & & & & 0.98 \\
\hline HPT, AVERAGE OF 3 & 0.94 & & & & \\
\hline STATIONS & & & & & \\
\hline
\end{tabular}

In order to minimize the inconsistencies in the time series of each one of the stations and to get an over the whole basin mean air temperature value, we calculated the average monthly mean values of these 3 stations for the period 1970-2001.

The mean annual and mean summer differences between NOA and CRU data (asterisks, light line), and also the differences between the corresponding 3 stations (Hellinicon, Nea Philadelfia and Tatoi) average values and CRU data (dots, heavy line), are shown in Figure 6.

As CRU data are anomalies from the 1961-90 period, NOA anomalies and the 3 station average anomalies from their corresponding long term mean were used for calculating their differences from CRU data. Again the NOA stations annual as well as summer air temperature values exhibit a jump on mid 1990s, which cannot be attributed to urban effect.

In order to test the assumption of artificial discontinuity in the NOA time series, the standard normal homogeneity test (SNHT) for single shift of the mean level, as developed by Alexandersson and Moberg (1997), is applied. Reference time series were created from the aggregation of the three neighboring to NOA stations $(\mathrm{H}, \mathrm{P}, \mathrm{T})$ time series.

The analyses are performed on the difference series, of the annual and also of the monthly deseasonalized values, created by subtracting each reference time series from the candidate station's corresponding time series. The break in the difference series has been found statistically significant $(P<0.01)$ on 1996 in the annual values and on December 1996 in the monthly values series (Table 3). A graphical example of the test on the difference series of 
monthly deseasonalized values created by the subtraction of the three stations $(H, P, T)$ averaged values from the corresponding NOA values, is shown in Figure 7 lower panel.

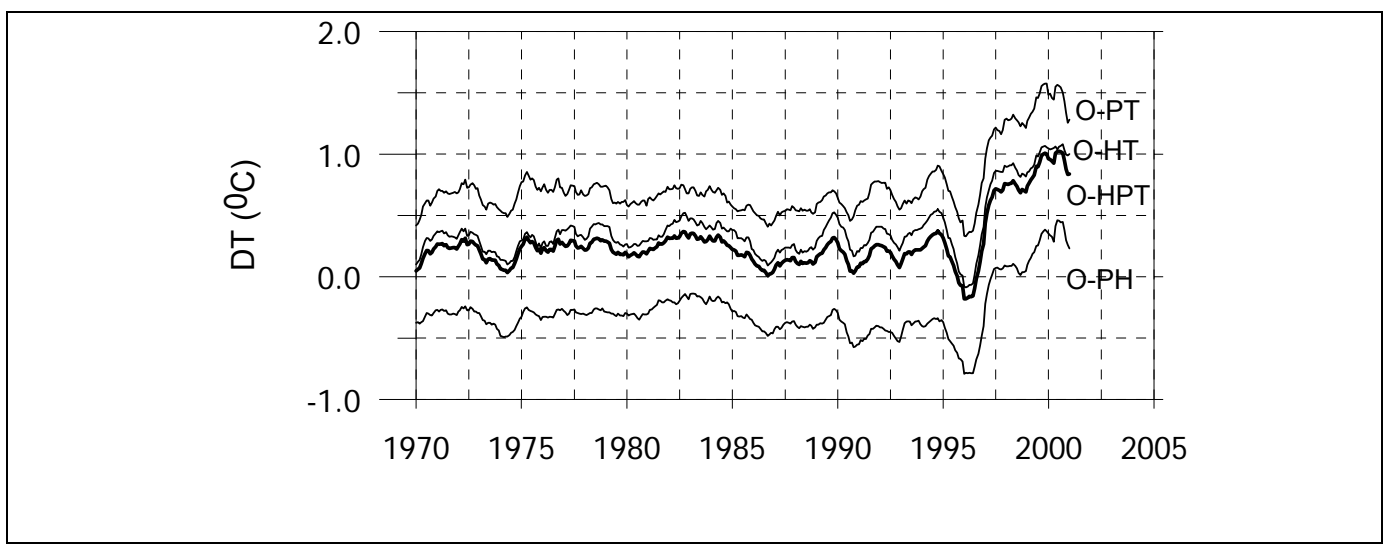

Figure 5. The 12 month running means (Jun 69 to May 70 average is plotted on Jan 70 ) of the differences of the National Observatory of Athens $(\mathrm{O})$ monthly mean air temperature minus the corresponding average of the 3 stations Hellinicon $(H)$, Nea Philadelfia $(P)$ and Tatoi $(T)$ value, (O-HPT, heavy line). Also, the 12 month running means of the differences of the NOA air temperature minus the corresponding average value of each pair of the other stations (O-PT, top line; O-HT, dashed line; O-HP, lower line) are displayed. The mid 1990s discontinuity is apparent in all the four curves.
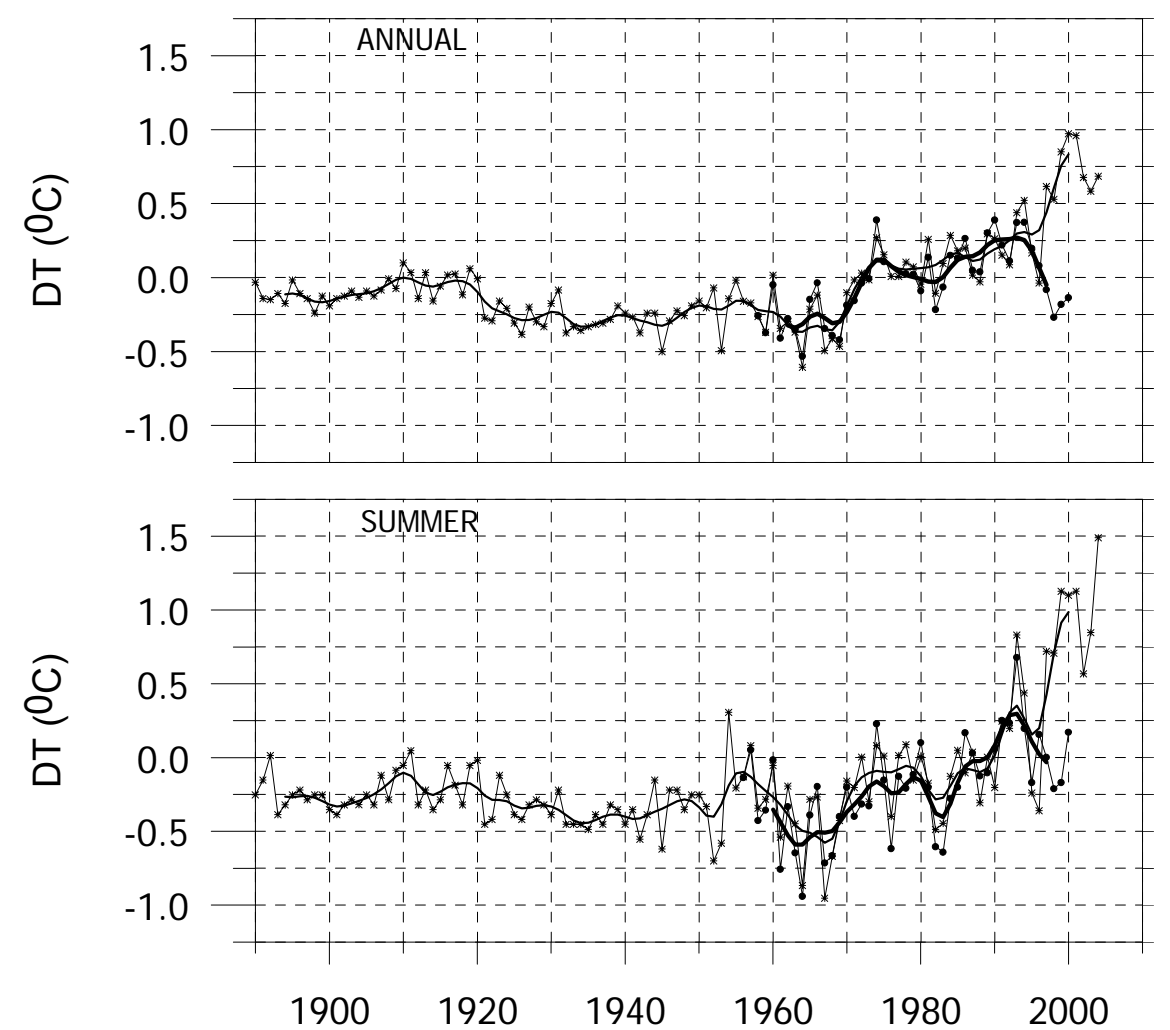

Figure 6. Asterisks and light line (9-year Gaussian smoothing) are the annual and summer mean air temperature differences between NOA anomalies (departures from long term mean) and the average anomalies of the grid box (CRU), which covers the entire continental Greece. Dots and heavy line are the corresponding differences between the average of the 3 station (Hellinicon, Nea Philadelfia and Tatoi) anomalies (departures from long term mean) and the CRU data. 
Furthermore the methodology for identifying discontinuity in time series and the time of change point, developed by Easterling and Peterson (1995) is applied on the above described difference time series. The Easterling and Peterson tests located a statistically significant $(P<0.01)$ discontinuity, again on 1996 in the annual values and on December 1996 in the monthly values, in all the constructed difference series (Table 3). A graphical example of the test on the difference series of monthly deseasonalized values created by the subtraction of the three stations $(H, P, T)$ averaged values from the corresponding NOA values is shown in Figure 7 upper and middle panel. As the change point remains constant throughout the set of tests and comparisons of the candidate station NOA with each pair of its neighboring stations, this discontinuity should be attributed to this candidate station (Table 3 ).

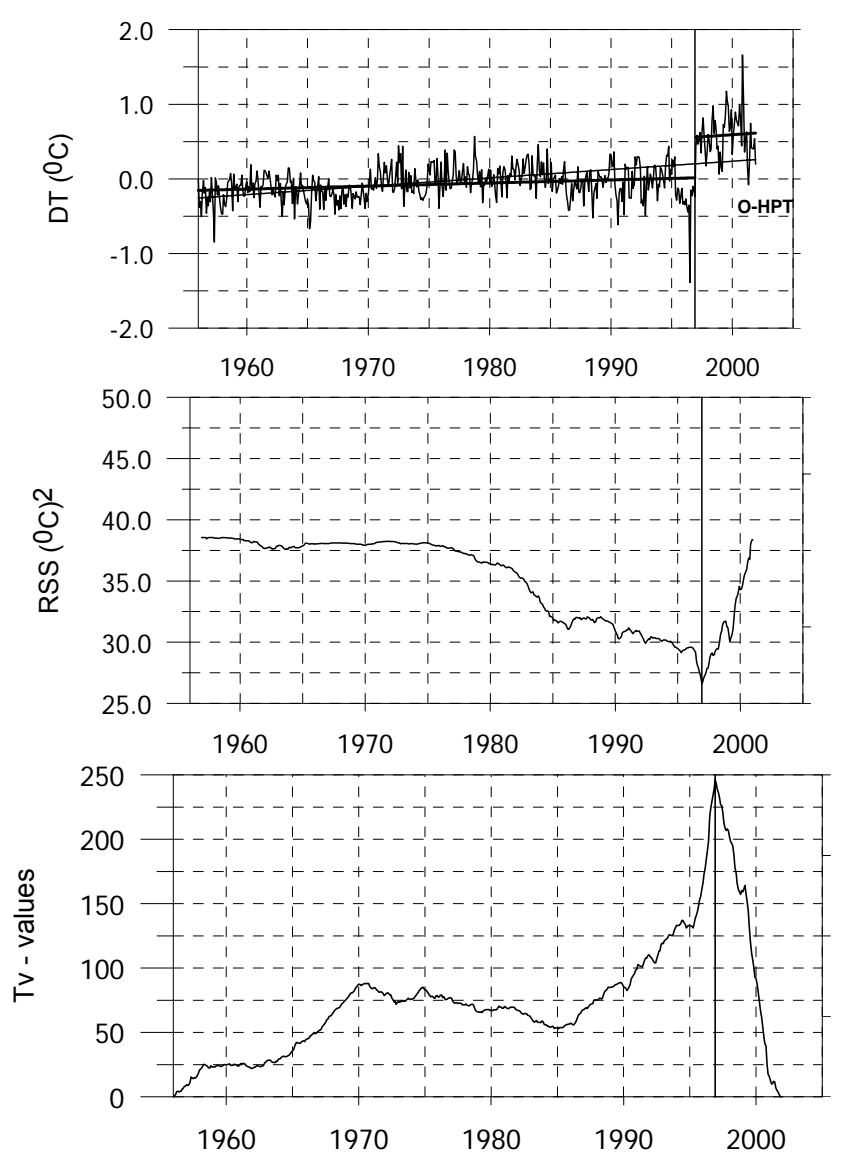

Figure 7. Time series of the differences between NOA and the 3 stations average HPT monthly deseasonalized air temperature values (upper panel). On top of this curve linear regressions fitted to the entire period (dashed line) and for the two sections, before and after the break (solid lines), are drawn. The middle panel shows the sequence of the sum of the residual sum of squares (RSS) before and after each point of the above difference series after EasterlingPeterson test. The minimum value (vertical line) locates the discontinuity point to be tested. The lower panel shows the sequence of $T_{v}$ values calculated from the means of the above difference series after being standardized according to Alexandersson test. $T$ maximum (vertical line) shows the tested break point.

Also Alexandersson test applied on the difference series of NOA monthly deseasonalized series minus the corresponding CRU grid time series, showed a change point on October 1996 ,very close to Decemper 1996, with statistically significant U value 130 . After this analysis it is obvious that besides the regional secular fluctuations and urbanization effect (since 1970s), there is an artificial discontinuity on 1996 in the air temperature records of the National Observatory of Athens with a shift of the mean level. Undoubtedly the statistically confirmed discontinuity on 1996, which succeeded the abrupt decrease in the NOA time series at 1995, must be attributed to the successive calibration trials of the newly installed thermometers at that time. The sharp gap of 1995 is not pointed out by the statistical tests probably because 
was of a short duration and therefore there is little chance that the tests will indicate nonhomogeneity. Therefore the NOA air temperature records must be treated with caution for long-term trends detection. Undisputable long-term trends for Greece are difficult to define, as on the other hand, the Hellenic Meteorological Service station's records are inadequate covering relatively short period of homogeneous observations.

Table 3. Statistical tests of the difference series (1956-2001)

Annual values

\begin{tabular}{|c|c|c|c|c|c|}
\hline \multirow{2}{*}{$\begin{array}{c}\text { Difference } \\
\text { Series }\end{array}$} & \multicolumn{3}{|c|}{ Easterling-Peterson test } & \multicolumn{2}{c|}{ Alexandersson test } \\
\cline { 2 - 6 } & $\mathrm{U}$ & $\mathrm{t}$ & $\begin{array}{c}\text { Break } \\
\text { date }\end{array}$ & Tmax & $\begin{array}{c}\text { Break } \\
\text { date }\end{array}$ \\
\hline O-HPT & 21.6 & -8.35 & 1996 & 27.6 & 1996 \\
\hline O-HP & 14.1 & -6.18 & 1996 & 24.0 & 1996 \\
\hline O-HT & 14.1 & -16.48 & 1996 & 24.4 & 1996 \\
\hline O-PT & 25.0 & -5.59 & 1996 & 27.2 & 1996 \\
\hline
\end{tabular}

\begin{tabular}{|c|c|c|c|c|c|}
\hline \multicolumn{1}{c|}{$\begin{array}{c}\text { Monthly deseasonalized values } \\
\text { Serference }\end{array}$} & \multicolumn{2}{|c|}{ Easterling-Peterson test } & \multicolumn{2}{c|}{ Alexandersson test } \\
\cline { 2 - 6 } & $\mathbf{U}$ & $\mathrm{t}$ & $\begin{array}{c}\text { Break } \\
\text { date }\end{array}$ & Tmax & $\begin{array}{c}\text { Break } \\
\text { date }\end{array}$ \\
\hline O-HPT & 82.0 & -16.2 & $\begin{array}{c}\text { Dec. } \\
1996\end{array}$ & 246 & $\begin{array}{c}\text { Dec. } \\
1996\end{array}$ \\
\hline O-HP & 65.0 & -12.1 & $\begin{array}{c}\text { Dec.1996 } \\
\text { Dec. } \\
1996\end{array}$ \\
\hline O-HT & 58.6 & -23.2 & $\begin{array}{c}\text { Dec. } \\
1996\end{array}$ & 204 & $\begin{array}{c}\text { Dec. } \\
1996\end{array}$ \\
\hline O-PT & 75.0 & -12.3 & $\begin{array}{c}\text { Dec. } \\
1996\end{array}$ & 193 & $\begin{array}{c}\text { Dec. } \\
1996\end{array}$ \\
\hline
\end{tabular}

The results of all tests reject the null hypothesis of no discontinuity $(P<0.01)$

$\mathrm{O}$, National Observatory of Athens; $\mathrm{H}$, Hellinikon Airport; P, Nea Philadelfia;

T, Tatoi Airport; HPT, HP, HT, PT, averaged corresponding stations' values.

NOA Institution has already started homogenization procedure of the air temperature time series and re-evaluation of the relevant trends.

\section{CONCLUSIONS}

In conclusion, from 1970 s to 1990 s there is a $0.3-0.4{ }^{\circ} \mathrm{C}$ gradual increase in the NOA air temperature time series comparing with the rural environment most likely due to urban effect. That increase appears also on the average in the other three neighboring urban stations. An evident additional warming of about $0.7^{\circ} \mathrm{C}$ as a jump in the NOA annual values time series on mid 1990s is attributed to the change of instruments in NOA station. Statistical tests applied on the time series of the differences of the NOA air temperature minus the corresponding averaged values of the urban stations, emerged a statistically significant discontinuity in NOA time series on 1996. Therefore, the recent trend of the NOA air temperature time series is artificial and does not reflect the global warming signal, thus is difficult to accept that the recent temperature variability in the NOA records is beyond the warming of the period from 1920s to 1950 s and also the maximum values recorded in the region during that period do not seem to be exceeded so far.

\section{ACKNOWLEDGEMENTS}

We acknowledge with thanks the Hellenic Meteorological Service, National Observatory of Athens and Climatic Research Unit of East Anglia University for providing the data.

\section{REFERENCES}

Alexandersson H. (1986) A Homogeneity test applied to precipitation data. Journal of Climatology 6: 661-675. 
Alexandersson H., Moberg A., (1997), Homogenization of Swedish temperature data Part I: Homogeneity test for linear trends. International . Journal of Climatology 17: 25-34.

Chronopoulou-Sereli, A., (1993), Thermal Air Pollution in Greater Athens Area. Proc. of the $3^{\text {rd }}$ Conference on Environmental Science and Technology, Lesvos, Greece, 6-9 September 1993, B, 191-197.

Easterling D., Peterson T., (1995), A New method for detecting undocumented discontinuities in climatological time series. International . Journal of Climatology 15: 369-377.

Englezou, J.F., Amanatidis, G.T., Helmis, C.G., (1993), Influence of the Urbanization on the Diurnal Variation of Temperature and Relative Humidity in the Athens Basin Proc. of the $3^{\text {rd }}$ Conference on Environmental Science and Technology, Lesvos, Greece, 6-9 September 1993, B, 438-446.

Feidas H., Makrogiannis T., Bora-Senta E., (2004), Trend analysis of air temperature time series in Greece and their relationship with circulation using surface and satellite data: 1955-2001. Theoretical and Applied Climatology 79:185-208.

IPCC, (2001), Intergovermental Panel on climate change, climate change: The scientific basis (Contribution of Working Group I to the $3^{\text {rd }}$ Assessment Report of the IPCC), Cambridge: Univ. Press, Cambridge.

Jones P.D., New M., Parker D.E., Martin S. and Rigor I.G., (1999), Surface air temperature and its variations over the last 150 years: Reviews in Geophysics 37, 173-199.

Jones P.D, Moberg A., (2003), Hemispheric and large-scale surface air temperature variations: An Extensive Revision and an Update to 2001. Journal of Climate 16: 206-223.

Jones P.D, Mann M.E. (2004), Climate over past millennia. Reviews in Geophysics 42: RG2002, 142.

Katsoulis B, Theoharatos G., (1985), Indications of the urban heat island in Athens Greece. Journal Climate and Applied Meteorology 24: 1296-1302.

Luterbacher J, Dietrich D. Xoplaki E. Grosjean M. Wanner H., (2004), European seasonal and annual temperature variability, trends, and extremes since 1500. Science 303: 1499-1503 (DOI:10.1126/science.1093877).

Metaxas D.A, Bartzokas A. and Vitsas A., (1991), Temperature fluctuations in the Mediterranean area during the last 120 years. International . Journal of Climatology 11: 897-908.

Mitchell T.D., Hulme M. and New M., (2002), Climate data for political areas. Area 34, 109-112

Mitchell T.D., Carter T.R., Jones P.D., Hulme M., and New M., (2003), A comprehensive set of high-resolution grids of monthly climate for Europe and the globe: the observed record (19012000) and 16 scenarios (2001-2100). Journal of Climate: Submitted.

New M., Lister D., Hulme M and Makin I., (2002), A High resolution data sets of surface climate over global land areas, Climate Resarch 21.

Philandras C.C, Metaxas D.A. Nastos P.T., (1999), 'Climate variability and urbanization in Athens'. Theoretical and Applied Climatology 63: 65-72.

Philandras C.M, Nastos P.T., (2002), The Athens urban effect on the air temperature time series of the National Observatory of Athens and New Philadelphia stations. Proc. of the $6^{\text {th }}$ Hellenic Conference in Meteorology, Climatology and Atmospheric Physics, Ioannina Greece, 25-28 September, 2002, 501-506.

Repapis C. C, Metaxas D. A., (1985), The Possible influence of the urbanization in Athens city on the air temperature climatic fluctuations at the National Observatory. Proc. of the 3rd HellenicBritish Climatological Congress, Athens, Greece 17-21April 1985,. 188-195.

Repapis C.C, Philandras C. M. (1988), A note on the air temperature trends of the last 100 years, as evidenced in the eastern Mediterranean time series. Theoretical and Applied Climatology 39: 93-107.

Repapis C, Philandras C.M., (1997), Air temperature trends in the Mediterranean basin. Proc. of the Eastern Europe and Global change Symposium, Kassandra, Halkidiki, Greece 3-10 October 1994, 133-138.

Saaroni H, Ziv B., Edelson J., Alpert P., (2003), Long term variations in summer temperature over the eastern Mediterranean. Geophysics. Research. Letters 30: No 18, 1946, doi:10.1029/2003GL017742.

Solow A., (1987), Testing for climatic change: an application of the two-phase regression model. Journal Climate and Applied Meteorology 26:1401-1405. 